\title{
Spatial and Temporal Variations of Gutenberg-Richter b-Values Using Classic Method of Moment (CMM) and Seismicity in and Around Van Lake
}

\author{
${ }^{* 1}$ Tuğba Türker and ${ }^{2}$ Yusuf Bayrak \\ ${ }^{* 1}$ Faculty of Engineering, Department of Geophysic Engineering Karadeniz Technical University, Turkey \\ ${ }^{2}$ Faculty of Engineering, Department of Geophysic Engineering Karadeniz Technical University, Turkey
}

\begin{abstract}
The aim of this study determined spatial-temporal variations of Gutenberg-Richter bvalues using the Classic Method of Moment (CMM) and seismicity in and around Lake Van. We wrote a Matlab program for this method in the Matlab system. The faults for the Van region used as updated in the GIS system given the reference from the different sources by Bayrak and Türker (will be used in the doctoral thesis). Around Lake Van divided into 4 different seismic source regions. For each seismic source region, probabilities ranging from 0 to 1 , the annual probability of exceedances and return periods were calculated for the next 25, 50 and 100 years. Van region determined the seismicity $b$ value changes, $\beta$-values. We mapped spatial variations of the $b$-values using the GIS system. As a result, Lake Van region (region 2) occurred 7.1 magnitude an earthquake in the next 100 years with $31 \%$ probability levels. If it occurred in the 50 years with $15 \%$ probability levels, in the 25 years with $7.8 \%$ probability levels. We estimated the low b-values in the Lake Van so, it has been the high seismicity and can be occurred an earthquake as the high magnitude in the next years. This study will be lead to earthquake hazard analysis and seismic hazard studies in and around Lake Van.
\end{abstract}

Key words: Classical Moment Method (CMM), Gutenberg-Richter b-values, in and around Lake Van.

\section{Introduction}

Statistical seismology focused on earthquake population (seismicity patterns) and their evolution in space and time. Statistical seismology contained a large range of contemporary subjects in current seismology research, such as earthquake self-similarity, seismic hazard analysis, the study of precursory phenomena, etc.

The East Anatolian Fault Zone (EAFZ) is seismically effective and a morphologically discrete left-lateral strike-slip fault and it enlarged for $\sim 400 \mathrm{~km}$ and created the Arabian/Anatolian plate boundary in southeastern Turkey. The EAFZ was together with its conjugate fault, the North 
Anatolian Fault, support coordinate the westward escape of the Anatolian plate from the Arabian/Eurasian collision zone. Morphotectonic features belong to the EAFZ aided maintain understandings into the nature of landscape development and helped understanding changes in tectonic activity and fault evolution (Toker et. al. 2017).

The Lake Van area was a seismically active region as indicated by historical and instrumental seismicity records. Lake Van was placed in Eastern Anatolia, Turkey, at a latitude of $1648 \mathrm{~m}$ above the sea level. Lake Van was a capacity water depth of almost 450m. It was the greatest lake in Turkey and at $576 \mathrm{~km}^{3}$ the fourth greatest terminal lake in the world. The lake measures $130 \mathrm{~km}$ from west-southwest to east-northeast and was a plane region of $3522 \mathrm{~km}^{2}$. The 23 October 2011 Van earthquake $\left(\mathrm{M}_{\mathrm{w}}=7.1\right)$ occurred in the NE part of Lake Van area, surprisingly on a fault (the Van fault) what was not available in the current active fault map of Turkey. But, the event of such a great magnitude earthquake in the region was not amazing concerning the historical seismicity of the region. The comparison of the damage patterns suggests that the earthquake is much likely a recurrence of the 1715 Van earthquake (Utkucu M. 2014).

We plotted epicenter distribution and 4 different seismogenic zones in and around Lake Van.

We used from faults in plotted new fault map by Bayrak and Türker (The thesis was using as plotted new fault map by Bayrak and Türker in the next 2019 year and it plotted in the ArcGIS with references maps of the different researchers) and divided into different seismogenic zones in and around Lake Van (Fig. 1). Türker et. al. (2017) investigated analysis of earthquake parameters using Bayesian Method in and around Lake Van. Türker and Bayrak investigated spatial and temporal variations with different methods. Türker and Bayrak (2017) spatial variations of b-values magnitude-frequency distribution from a Bayesian Approach based on spline smooth (b spline) function and Karlıova Triple junction (Eastern Turkey). Türker et. al. (2017) investigated analysis of spatial and temporal variation of earthquake hazard parameters from a Bayesian approach in and around the Marmara Sea.

The region 1 contained Şemdinli-Yüksekova Fault Zone, Southeast-Anatolian thrust, Cizre fault, Yayla Fault. The region 2 contained Temrenli fault system, Dorutay fault, Saray Fault Zone, Başkale fault, Erciş, Tutak faults, Hamur, Patnos, Bulamaç, Özyurt, Ataköy, Karasu, Çarpanak, Yeniköşk, Kalecik Van, Gürpınar faults, Süphan fault zone, Van fault zone. The region 3 contained 
Horasan, Kağızman, Ağrı, Doğubeyazıt faults, Arpalı fault system, Iğdır fault zone, Lake Balık fault zone. The region 4 contained Palandöken, Dumlu, Karayazı, Akdağ, Kazbel, Karaçoban, Naziklake, Lake Akdoğan, Bulanık, Malazgirt faults, Erzurum, Çat, Varto, Muş, Kavakbaşı fault zones.

The catalog plotted according to changes in the depth and magnitude values in the different years (Fig. 2). We used classic moment method for temporal and spatial variations estimated Gutenberg-Richter b-values in and around Lake Van (Fig. 3). The probability of exceedance annual probability of exceedance and return periods graphs plotted in and around Lake Van (according to the future 25, 50, 100 years) ( Fig. 4). The spatial variations of the b-values mapped with the GIS program for region 1, 2, 3 and 4 different regions in and around Lake Van (Fig. 5).

\section{Materials and Method}

\subsection{The earthquake magnitude-frequency distribution}

The statistics of earthquakes important a subject of investigation for a long time. Gutenberg and Richter (1954) achieved that the size distribution of regional earthquakes followed up a power law over the entire range of observed events. This law distribution was called the "Gutenberg-Richter" distribution, a completely accepted empirical formula what founded a correlation between earthquake occurrence frequencies and magnitudes with two parameters, a and $b$.

While the low b-value required that a larger fraction of seismic events occur at larger magnitudes, the high $b$-value required that a smaller fraction of the total event count occurs at larger magnitudes.

\subsection{Classic Method of Moments (CMM)}

The magnitudes of the observed earthquakes are in descending order up to M1, M2,.., MN, and $\mathrm{N}$ indicates the number of events.

If the magnitude-frequency distributions conform to the Gutenberg-Richter law, the approximation relationship for the moment of $\gamma$ is given below (Eq. 1): 
$\sum_{i=1}^{N}\left(M_{i}-M_{0}\right)^{\gamma} \approx N \Gamma(\gamma+1) /(\mathrm{bLn} 10)^{\gamma}$

Here, the integral can be renewed by addition. Utsu (1965) set an estimate for $\gamma=1$ and developed the following formula (Eq. 2):

$\mathrm{b}=\operatorname{Lne} / \frac{1}{\mathrm{~N}} \sum_{i=1}^{N}\left(M_{i}-M_{0}\right)$

This estimate is equal to the maximum probability method (Aki, 1965). In general, the following formulation is obtained for the value $\gamma$ (Eq. 3):

$\mathrm{b}_{\gamma}=\Gamma(\gamma+1)^{\frac{1}{\gamma}} / \operatorname{Ln} 10 \mathrm{~J}_{\gamma}^{1 / \gamma}$

$\mathrm{J}_{\gamma}=\frac{1}{\mathrm{~N}} \sum_{\mathrm{i}=1}^{\mathrm{N}}\left(\mathrm{M}_{\mathrm{i}}-\mathrm{M}_{0}\right)^{\gamma}$

Method of moments (MM): i ( $\alpha \mathrm{i}, \beta \mathrm{i}, \gamma \mathrm{i})$ parameters can be calculated for each segment as $\mathrm{i}=1, \ldots$ .., s (Eq. 4):

$\widehat{\alpha_{l}}=4 \widehat{\mu_{2}^{3}} / \widehat{\mu_{3}^{2}} / \widehat{\beta_{l}}=2 \widehat{\mu_{2}} / \widehat{\mu_{3}} / \widehat{\gamma_{l}}=\widehat{\mu_{1}}-2 \widehat{\mu_{2}^{2}} / \widehat{\mu_{3}}$

$\widehat{\mu_{k}} ;$ moment magnitude sample.

And the $\beta$ value, ns, is calculated as the weighted average of the estimated values (Eq. 5):

$\hat{\beta}=\sum_{i} W_{i} \widehat{\beta}_{l} / \sum_{i} W_{i}$

And the Wi value: the variance of $\widehat{\beta}_{l}$ value.

\section{Results}

Temporal-spatial variations estimated Gutenberg-Richter b-values using the Classic Moment Method (CMM) to determined seismicity in and around Lake Van. The Matlab program wrote for this method and the parameters estimated relationship the seismicity. The faults used as updated give reference from different sources at the GIS environment by Bayrak and Türker in and around Lake Van. Around Lake Van divided into 4 different seismic source regions. The annual probability of exceedances and return periods are calculated for each seismic source region in the next 25, 50 and 100 years. 


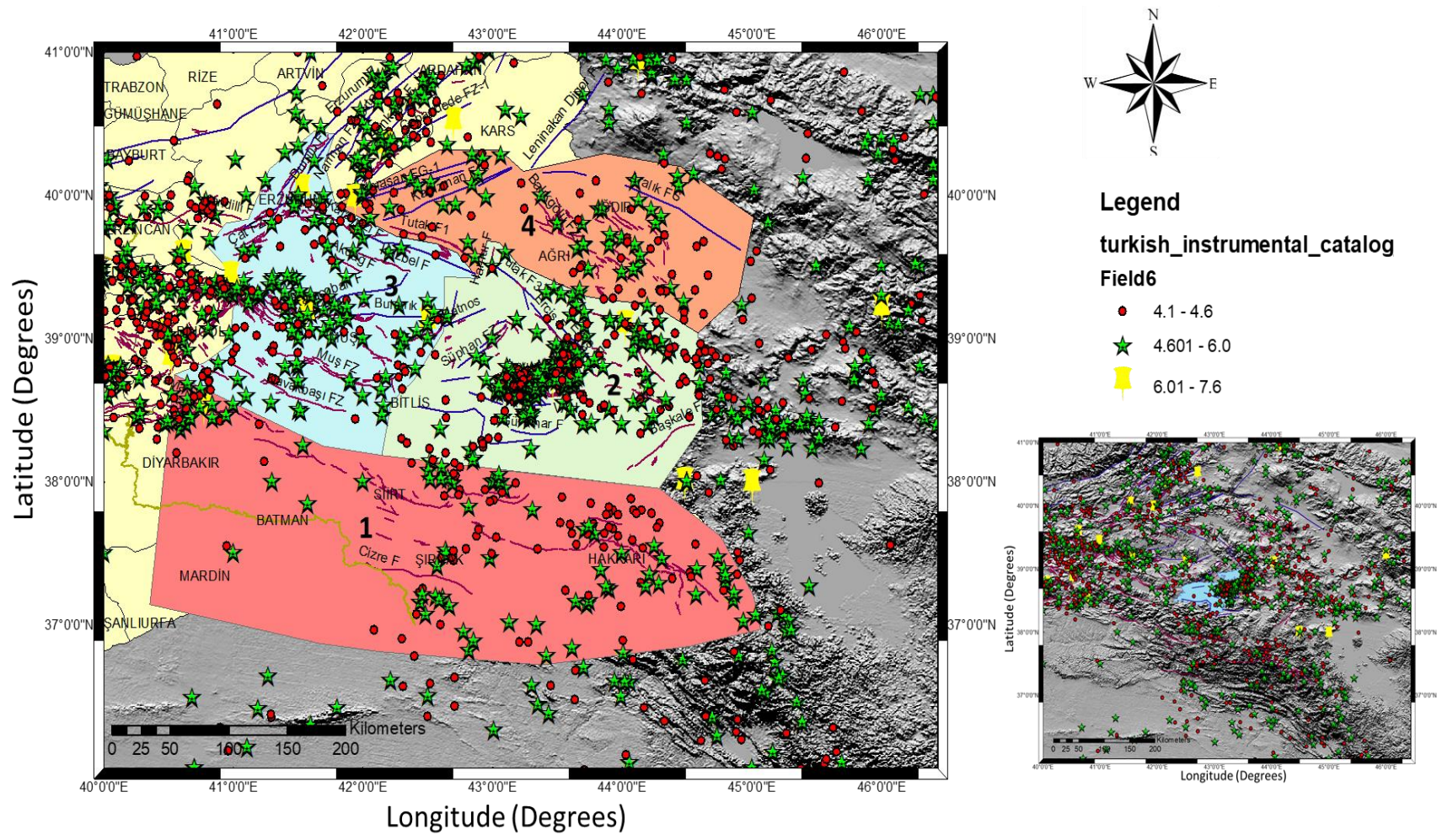

Figure 1.The epicenter distribution map and 4 different seismogenic regions mapped in Lake Van region (region 2)
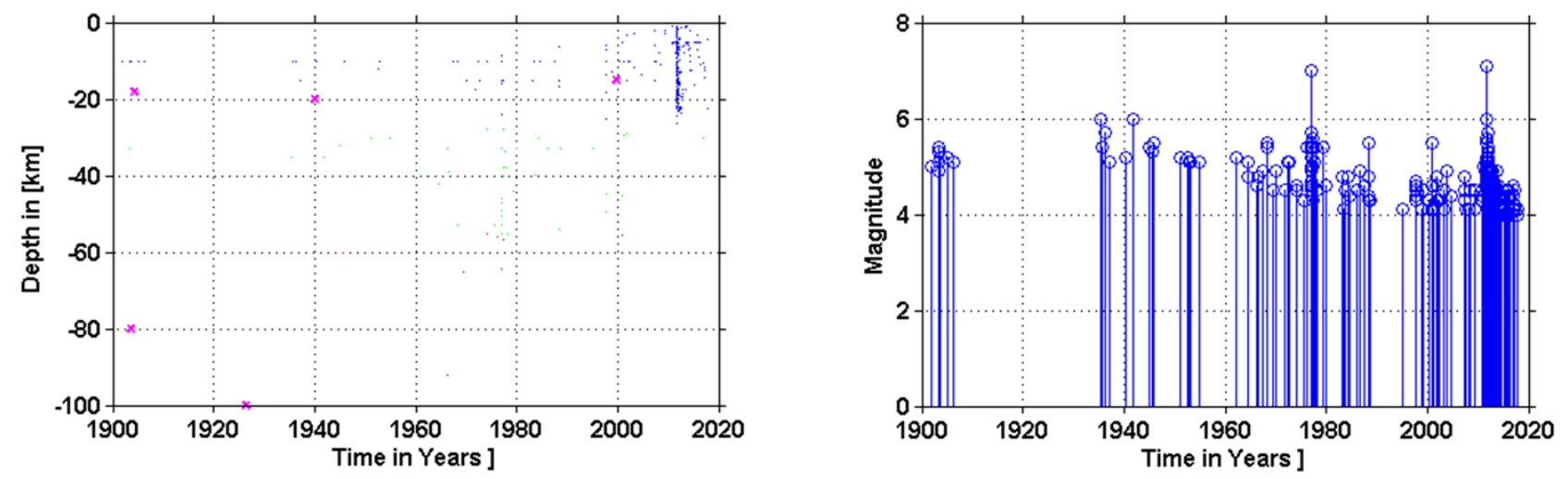

Figure 2.The magnitude and depth distribution of the earthquakes mapped in Lake Van region (region 2) 

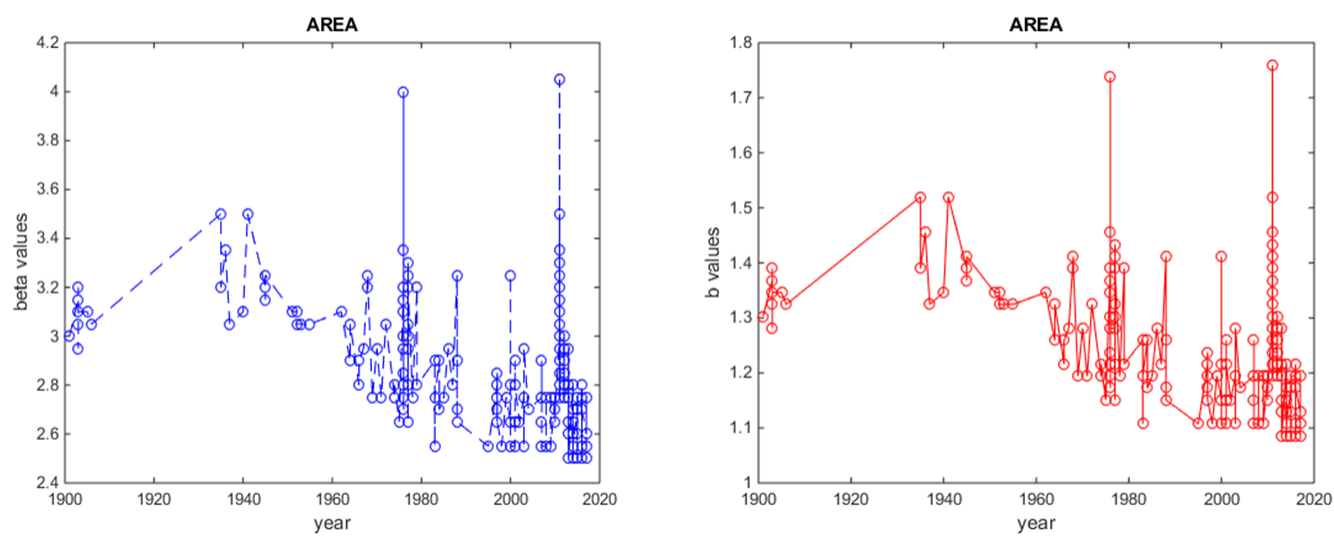

Figure 3.The temporal variations of $b$-values, $\beta$-values graphs plotted in Lake Van region (region 2)
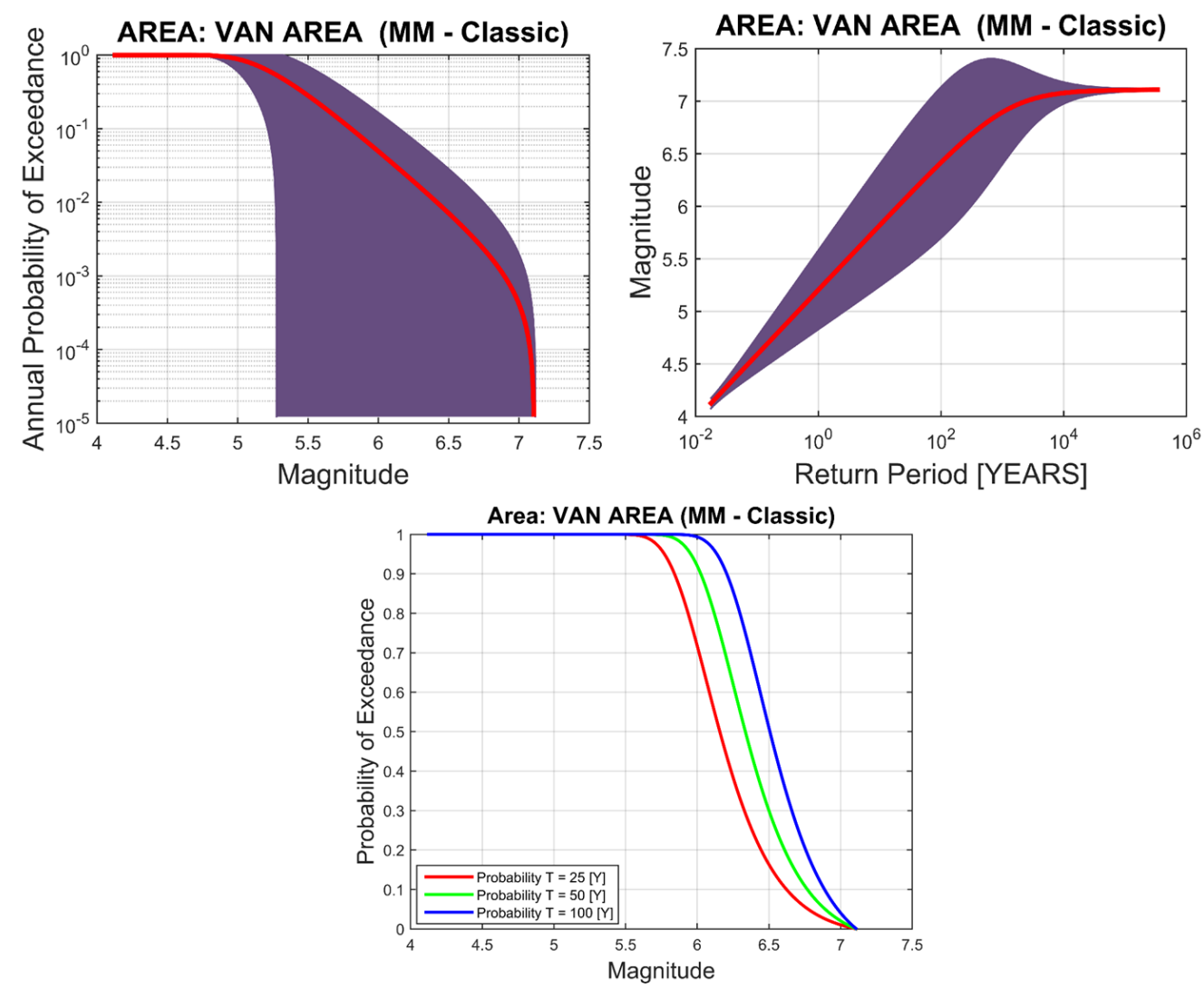

Figure 4. The probability of exceedance (according to the next 25-50-100 years), the annual probability of exceedance and return periods graphs plotted in Lake Van region (region 2) 

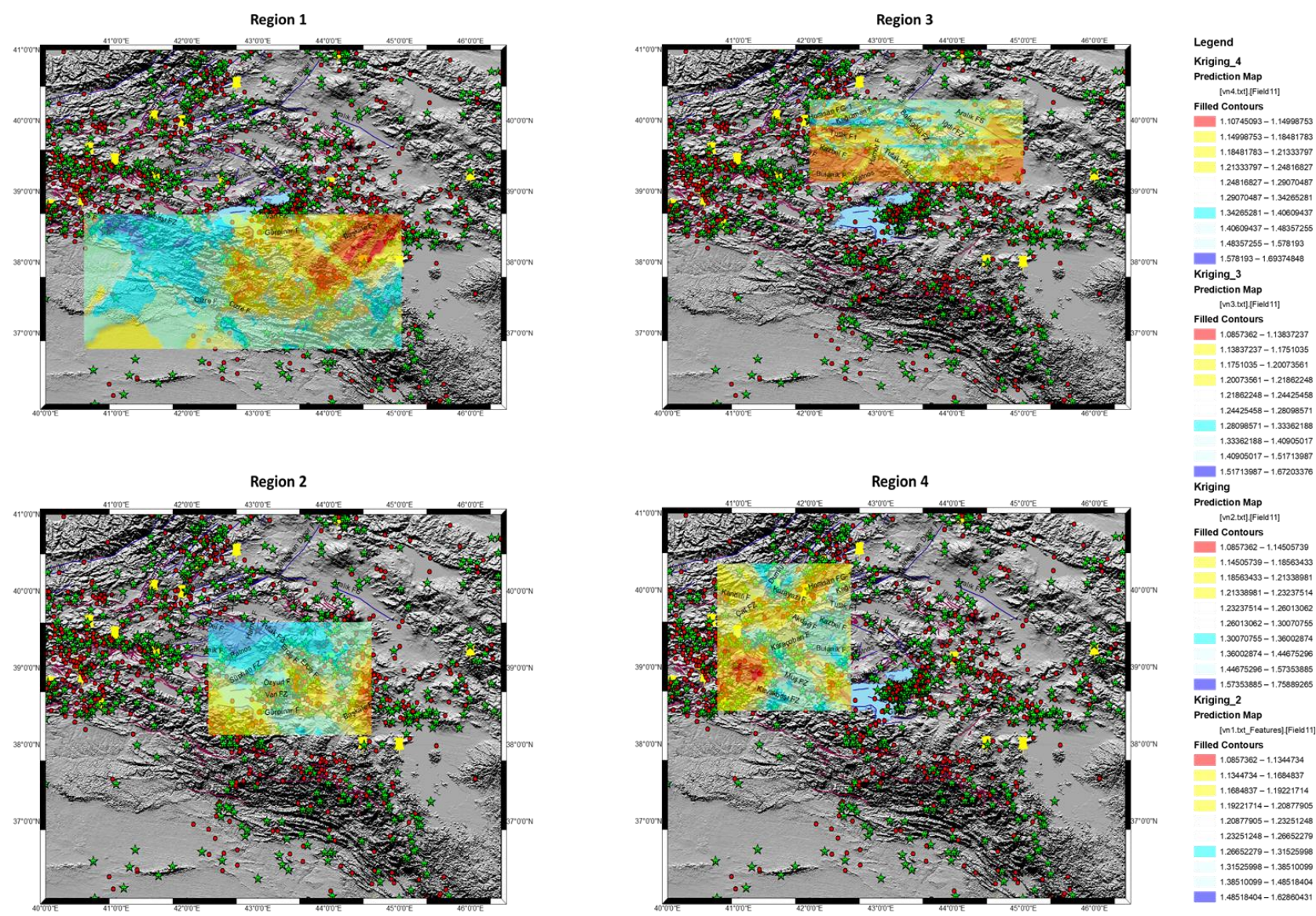

Figure 5.The spatial variations of the b-values mapped with GIS program for 4 different regions in Lake Van region (region 2)

Lake Van region calculated high $b$ value changes, beta values. The $\beta$ - values changed between 2.4-4.2 values and the $b$-values changed between 1.08-1.75. The spatial variations of the b values estimated using the GIS system. As a result, Lake Van region (region 2) occurred 7.1 magnitude an earthquake in the next 100 years with $31 \%$ probability levels. If it occurred in the next 50 years with $15 \%$ probability levels, in the next 25 years with $7.8 \%$ probability levels. According to spatial variations of the b-values: The region 1 estimated high b-values (red color parts on the map) between 1.48-1.62, low b-values estimated between 1.08-1.13 (blue color on the map). The region 2 estimated high b-values (red color parts on the map) between 1.57-1.75, low bvalues estimated between 1.08-1.14 (blue color on the map). The region 3 estimated high b-values (red color parts on the map) between 1.51-1.67, low b-values estimated between 1.08-1.13 (blue color on the map). The region 4 estimated high b-values (red color parts on the map) between 1.57- 
1.69, low b-values estimated between 1.07-1.14 (blue color on the map). The different regions estimated different $b$-values on the spatial maps. The region 1 estimated high $b$-value in the Başkale Fault but the estimated low b-value in the Southeast Anatolian Thrust. The region 3 estimated low b-values in the Lake Balık fault zone also it has been the high seismicity. The region 4 estimated the high b-values in Muş fault zone so, it has been low seismicity. If other parts have been the high seismicity. The region 2 estimated the high b-value in Saray fault zone and Temrenli fault but estimated low b-values in Lake Van. So, Lake Van has been the high seismicity and occurred an earthquake in the next years. This paper will be used earthquake hazard analysis and seismic hazard studies in and around Lake Van.

\section{References}

[1] Aki K. Maximum likelihood estimate of $\mathrm{b}$ in the formula $\log \mathrm{N}=\mathrm{a}-\mathrm{bM}$ and its confidence limits. Bull. Earthq. Res. Inst. TokyoUniv.1965; 43: 237-239.

[2] Utkucu M, Budakoğlu E, Yalçın H, Durmuş H, Gülen L, Işık E. Seismotectonic Characteristic of the 23 October 2011 Van (Eastern Anatolia) Earthquake (Mw=7.1). Bulletion of the Earth Sciences Application and Research Centre of Hacattepe University. 2014; 35(2): 87-108.

[3] Utsu T. A method for determining the value of $b$ in the formula $\log n=a-b M$ showing the magnitude-frequency relation for earthquakes (with English summary). Geophys. Bull. Hokkaido Univ.1965; 13: 99-103.

[4] Türker T, Bayrak Y, Bayrak E. Analysis of Earthquake Parameteers using Bayesian Method in and around Lake Van, Eastern Turkey. 2nd International Conference on Advances in natural and Applied Sciences, Antalya. 2017; 368.

[5] Türker T, Bayrak Y, Bayrak E. Analysis of spatial and temporal variation of earthquake hazard parameters from a Bayesian approach in and around the Marmara Sea. 4. UDMSK conference 2017.

[6] Türker T, Bayrak Y. Spatial variations of b-values magnitude-frequency distribution from a Bayesian Approach based on spline smooth (b spline) function and Karlıva Triple junction (Eastern Turkey). IV. International multidisciplinary congress of Eurasia (IMCOFE). 2017.

[7] Toker M, Şengör AMC, Schluter FD, Demirbağ E, Çukur D, Imren C, Niessen F. The structural elements and tectonics of the Lake Van basin (Eastern Anatolia) from multi-channel seismic reflection profiles. Journal of African Earth Sciences 2017; 129:165-178. 